\title{
Cumulative sum failure analysis for eight surgeons performing minimally invasive direct coronary artery bypass
}

David M. Holzhey, MD, Stephan Jacobs, MD, Thomas Walther, MD, PhD, Michael Mochalski, MD, Friedrich W. Mohr, MD, PhD, and Volkmar Falk, MD, PhD

Supplemental material is available online.
From the Department of Cardiac Surgery, Heart Center Leipzig, Leipzig, Germany.

Received for publication Nov 11, 2006; revisions received March 14, 2007; accepted for publication March 20, 2007.

Address for reprints: David M. Holzhey, MD, Herzzentrum Leipzig, Strümpellstraße 39 04289 Leipzig, Germany (E-mail: dholzhey@web.de).

J Thorac Cardiovasc Surg 2007;134:663-9

$0022-5223 / \$ 32.00$

Copyright (C) 2007 by The American Association for Thoracic Surgery

doi:10.1016/j.jtcvs.2007.03.029
Objective: Analysis of average and individual surgical performance for minimally invasive direct coronary artery bypass was used to enhance quality control for that operation.

Methods: A total of 1441 standard minimally invasive direct coronary artery bypass procedures performed from August 1996 to January 2006 were analyzed for mortality and 10 other major perioperative complications. Learning curves and assessment of perioperative outcome were calculated using descriptive statistics and cumulative sum observed minus expected failure analysis for 8 involved surgeons with a personal experience ranging from 27 to 443 procedures.

Results: The incidence of in-hospital mortality was $0.9 \%$ and compared favorably with the predicted mortality calculated by the logistic EuroSCORE $(3.6 \%, P<.01)$. Cumulative sum analysis revealed that 2 surgeons crossed the $95 \%$ reassurance boundary after 50 operations and that 2 surgeons crossed the $95 \%$ reassurance boundary after 100 operations. There were significant differences between surgeons with regard to the learning curves and perioperative complications $(3.6 \%-29.6 \%, P$ $<.01$ ). Two surgeons crossed the $95 \%$ alarm-line indicating unacceptably high failure rates.

Conclusions: Minimally invasive direct coronary artery bypass has become a procedure with low mortality and low complication rates, but results are case-load and surgeon dependent. Cumulative sum analysis is a valuable method allowing for a breakdown of complication rates over time displaying individual surgeons' strengths.

$\mathrm{F}$ or several years, quality assurance has become increasingly important in cardiac surgery. De Leval and colleagues ${ }^{1}$ and Carthey and colleagues ${ }^{2}$ outlined the importance of analysis of human factors in cardiac surgery and individual failure analysis. Minimally invasive direct coronary artery bypass (MIDCAB) grafting has been performed since 1996 in a standardized way at our institution. With the high number of MIDCAB procedures performed under similar conditions, it is not only possible to describe the outcome and complication rate of the procedure but also possible to compare individual surgeons' performances and learning curves.

The usefulness of the sequential probability cumulative sum (CUSUM) technique to analyze surgical performance has been shown in recent publications. ${ }^{3-6}$ It allows for detection of changes in perioperative mortality and morbidity during the patient care process. It provides almost real-time monitoring of surgical performance if updated after each procedure. ${ }^{3}$ CUSUM analysis acknowledges the importance of individual experience in monitoring performance and allows for easy charting of a learning curve with regard to the incidence of perioperative complications. The charts are intuitively readable, but care is needed to avoid misinterpretation. ${ }^{7}$ The CUSUM method is able to demonstrate changes in the patient care process as a whole regardless of where these 


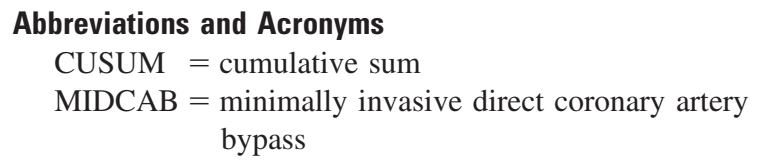

changes originate. Comparing results between different surgeons often fails because of the case mix and the variety of variables influencing patient outcome. Several risk-adjusted methods have been suggested for this scenario. In this study, no risk adaptation was used for the reasons outlined in the discussion.

With the quantity of MIDCAB operations at our institution performed under a standardized protocol (equal patient origin and patient selection, standardized surgical technique, identical postoperative management and medication), we found the non-risk-adjusted methods most practical and sufficient to evaluate and compare individual surgical performance over time.

\section{Materials and Methods}

From August 1996 to January 2006, 1441 patients underwent MIDCAB at our institution following a standardized protocol. The surgical technique has been described. ${ }^{8}$ Eight surgeons were involved in the MIDCAB program, achieving a different level of experience ranging from 27 to 443 operations. Five surgeons performed more than 100 operations. Written and electronic files of all patients were screened for demographic data, risk factors, intraoperative parameters, and postoperative short-term and longterm complications and outcome. All data were entered into a database, and standard descriptive statistical and CUSUM analyses were conducted using Microsoft Office Excel (Microsoft Corp, Redmond, Wash) and SPSS 10.0 (SPSS Inc, Chicago, Ill).

\section{CUSUM Analysis}

Cumulative failure charts and their use have been described. ${ }^{3-6}$ In this study, non-risk-adjusted cumulative observed minus expected failure charts were used. The statistical principles were adapted from the comprehensive tutorial by Rogers and colleagues. ${ }^{3}$ CUSUM was defined as $\mathrm{S}_{\mathrm{n}}=$ where $\mathrm{X}_{\mathrm{i}}=1$ for a "failure" (intraoperative conversion, death, or any major complication as defined in Table 1 ) and as $X_{i}=0$ for a complete "success" (none of the above complications). The target value $\mathrm{p}_{0}$ was set to 0.1 , indicative of an "acceptable failure rate" of $10 \%$ according to previous publications ${ }^{4,5}$ and our own experiences with off-pump coronary artery bypass surgery.

CUSUM curves, together with control boundaries, were calculated and drawn according to the formulas shown in the Appendix. The crossing of an upper boundary was interpreted as an increase of the failure rate to an unacceptably high level of $\mathrm{p}_{1}=0.2$, whereby crossing the upper $80 \%$ boundary set off a mild alarm to the surgeon and
TABLE 1. Definition of major complication

\begin{tabular}{|c|c|}
\hline Major Complication & Definition \\
\hline Conversion & $\begin{array}{l}\text { Necessity for any intraoperative } \\
\text { conversion to sternotomy or use } \\
\text { of CPB }\end{array}$ \\
\hline Mortality & $\begin{array}{l}\text { Death in hospital or within } 30 \mathrm{~d} \\
\text { after the date of operation }\end{array}$ \\
\hline Myocardial infarction & $\begin{array}{l}\text { Postoperative myocardial infarction } \\
\text { as confirmed by ECG findings or } \\
\text { significantly high levels of CK/ } \\
\text { CKMB }\end{array}$ \\
\hline Reintervention & $\begin{array}{l}\text { Necessity for postoperative } \\
\text { reintervention on the target } \\
\text { vessel }\end{array}$ \\
\hline IABP/ECMO & $\begin{array}{l}\text { Necessity for use of IABP and/or } \\
\text { ECMO in low cardiac output }\end{array}$ \\
\hline Rhythm disorder & $\begin{array}{l}\text { New onset of atrial fibrillation, need } \\
\text { for pacemaker implantation, } \\
\text { ventricular tachycardia, or } \\
\text { ventricular fibrillation }\end{array}$ \\
\hline Stroke & $\begin{array}{l}\text { Permanent neurologic impairment } \\
\text { caused by stroke or intracerebral } \\
\text { hemorrhage }\end{array}$ \\
\hline Bleeding & $\begin{array}{l}\text { Reoperation for bleeding usually } \\
\text { indicated when chest tube output } \\
\text { exceeded } 1000 \mathrm{~mL} \text { or x-ray } \\
\text { indicated hematothorax }\end{array}$ \\
\hline Renal & $\begin{array}{l}\text { Acute renal failure requiring } \\
\text { temporary hemofiltration }\end{array}$ \\
\hline Pulmonary & $\begin{array}{l}\text { Prolonged ventilation }(>24 \mathrm{~h}) \text {, } \\
\text { reintubation, and/or severe } \\
\text { pneumonia that prolonged } \\
\text { hospital stay }\end{array}$ \\
\hline Sepsis & $\begin{array}{l}\text { Occurrence of sepsis or intestinal } \\
\text { ischemia }\end{array}$ \\
\hline
\end{tabular}

$C P B$, Cardiopulmonary bypass; $E C G$, electrocardiogram; $C K$, creatine kinase; $I A B P$, intra-aortic balloon pump; ECMO, extracorporeal membrane oxygenation.

crossing the upper 95\% boundary gave reason for more thorough investigation. Crossing the lower $95 \%$ boundary led to the conclusion that the complication rate of the particular surgeon was equal to or below the accepted rate of $\mathrm{p}_{0}$. The curve moving in between the boundary lines indicated lack of statistic significance and triggered merely further monitoring (Figures E1, E2, and E3).

Whereas crossing the boundary lines is equivalent to a significant result in statistical testing, the comparison between surgeons is merely visual.

\section{Results}

\section{Operation Times}

Median operation times were between 100 and 138 minutes. One surgeon (surgeon E) reached a median operation time of 61 minutes. There was a wide range from 40 to 350 

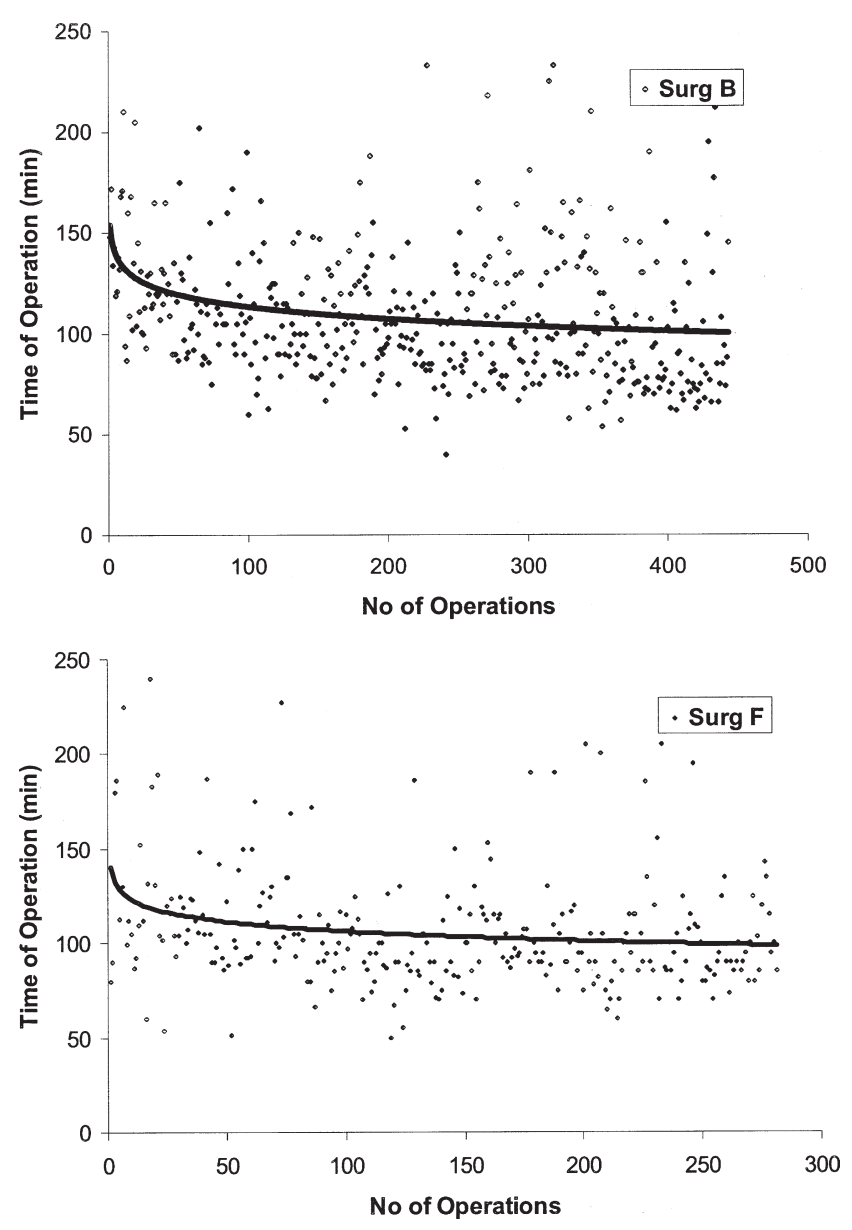

Figure 1. Learning curves of operation time and logarithmic regression trend lines.

minutes, and the duration of a MIDCAB operation can hardly be predicted. It was not possible to construct a "typical" learning curve with regard to operating time for every surgeon. Some operators needed the same average time throughout their whole experience. For the 2 most experienced surgeons (surgeons B and F), the learning curve for the operation time was calculated using logarithmic regression and is shown in Figure 1.

The trend graphs confirm the presumed shape with a relatively steep slope at the beginning. The individual operation times are different, and the trend is only a rough approximation.

\section{Overall Complication Rate}

The incidence of in-hospital mortality was $0.9 \%$ and compared favorably with the predicted mortality calculated by the logistic EuroSCORE of 3.6\% $(P<.01)$. The logistic regression version of the EuroSCORE can be calculated using the same risk factors as those for the EuroSCORE

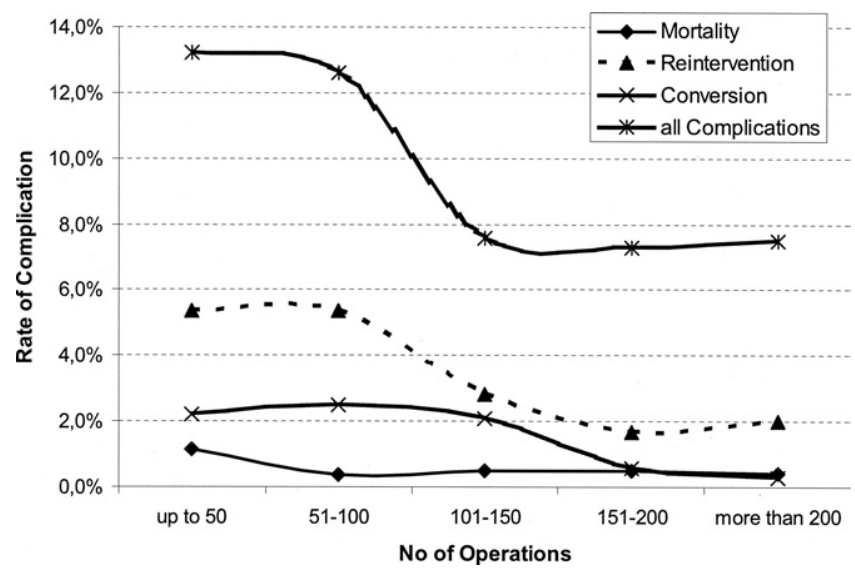

Figure 2. Average development of the most important complication rates.

value. For a given patient, the logistic EuroSCORE predicts the risk of perioperative mortality. (For further details, see http://euroscore.org.) The need for reintervention in $4.0 \%$ of the patients seems to be relatively high and may partly be explained by the fact that during the first years approximately half of the patients (709 patients) underwent routine postoperative angiography for quality control during the first postoperative days. Thereby, some asymptomatic patients with a less then optimal surgical outcome were detected, and, subsequently, repeat revascularization was performed.

Despite individual differences between surgeons, 3 stages of experience could be identified after analysis of average performance and individual learning curves (see below). After the "learning phase" $(<50$ operations) perioperative mortality decreased from $1.1 \%$ to $0.4 \%(P=$ .204). At the end of the "intermediate phase" (up to 100 operations), the overall complication rate and need for reintervention decreased from $12.7 \%$ to $7.1 \%(P<.001)$ and $5.1 \%$ to $2.8 \%(P<.001)$, respectively. The following "expert phase" ( $>100$ operations) was characterized by few complications for most surgeons. The need for intraoperative conversion to sternotomy decreased from $2.7 \%$ to $0.2 \%$ $(P<.001)$ after 150 operations. Figure 2 shows the average rates of mortality, need for intraoperative conversion, need for reintervention, and relative occurrence of any major complication with growing MIDCAB experience.

\section{Individual Surgeons' Statistics}

Descriptive statistics are widely used to evaluate a surgeon's individual performance. The total number of operated cases, the preoperatively mortality risk calculated with the EuroSCORE, and the frequency of complications for every surgeon are listed in Table 2. Although these statistics are easily understood, they reflect only part of the truth. 
TABLE 2. Incidence of major complications

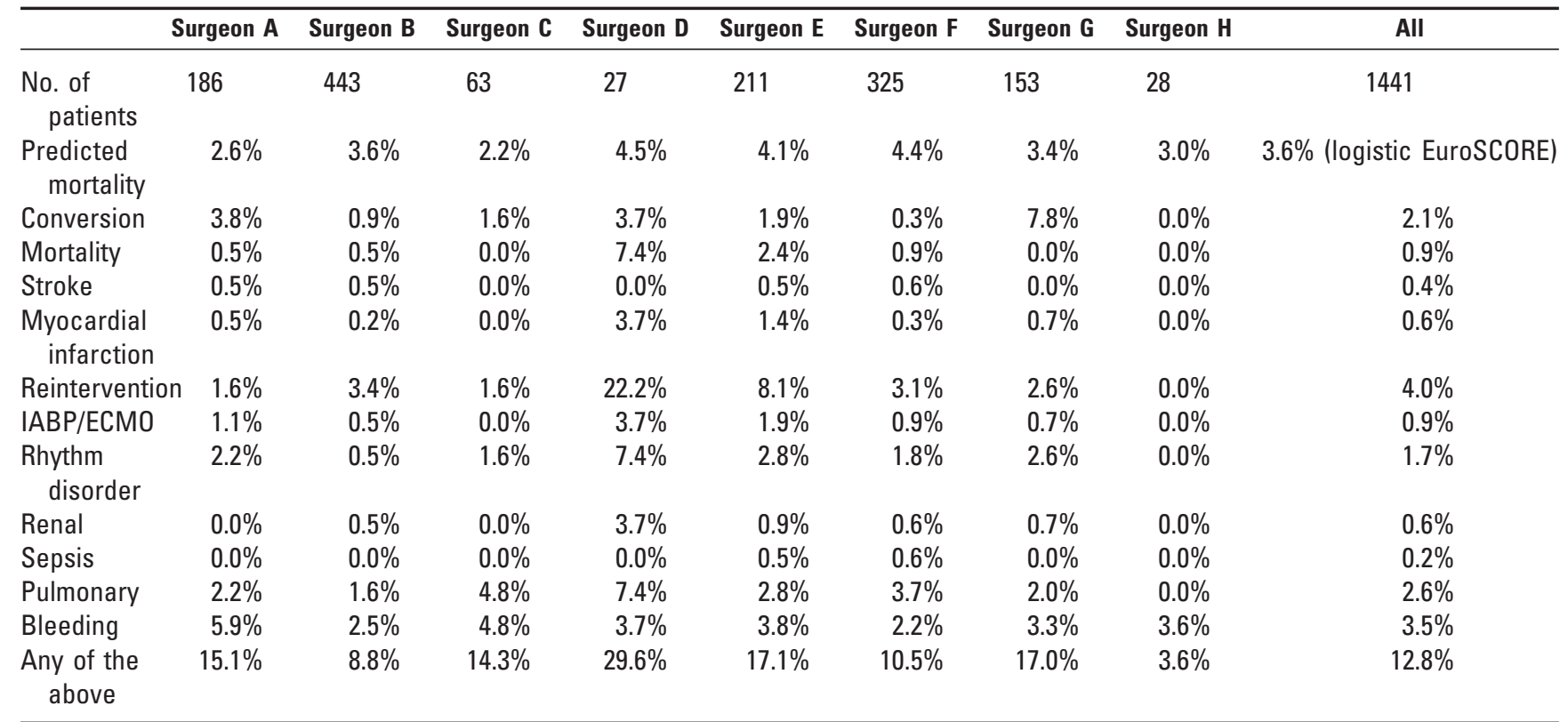

$I A B P$, Intra-aortic balloon pump; ECMO, extracorporeal membrane oxygenation.

Particularly for surgeons with little experience (surgeons D and $\mathrm{H}$ ), the mere percentage is of questionable statistical value and may be an exaggeration in either direction.

CUSUM curves react sensitively to irregularities in the patient care process so as to be an early marker of inherent errors in the system. For correct interpretation of the graphs, it is important to note that they do not reflect the patients' eventual outcome but merely depict periprocedural complications.

Surgeons with little experience. Surgeon D demonstrated an unacceptably high complication rate after 20 operations. This fact is also reflected in the absolute numbers (Table 2). He has left the program. Surgeon $\mathrm{H}$ was performing well, but his total experience was too small to allow for a valid statement. Surgeon $\mathrm{C}$ had an experience of approximately 60 operations and an average performance; statistics were still inconclusive (Figure 3).

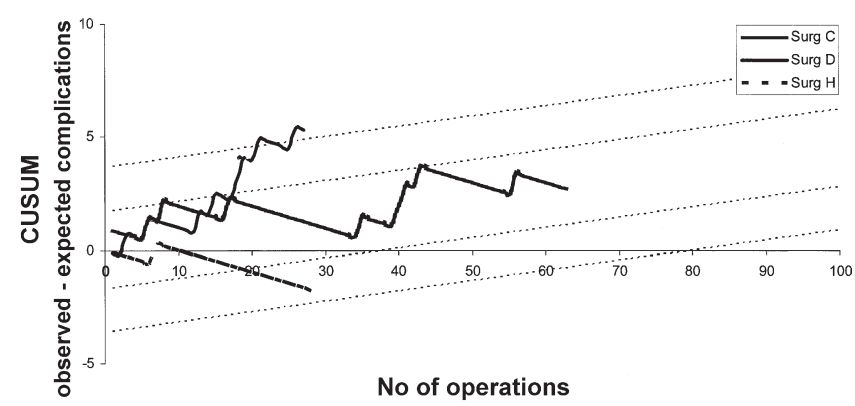

Figure 3. CUSUM charts of surgeons with little experience (with $80 \%$ and $95 \%$ boundary lines). CUSUM, Cumulative sum.
Surgeons with intermediate experience. Surgeon E was facing a steep increase in his complication rate after 70 operations. On closer analysis the main problem was a high frequency of in-hospital reinterventions (surgical or interventional) for anastomosis stenosis. It is interesting that this surgeon required only two thirds of the average operation time. As the surgeon became aware of the problem, the results improved toward the end of the period under review. Surgeon A went through the "typical" learning process up to operation 150. After that, an upward slope of postoperative complications occurred mainly as the result of postoperative bleeding. The surgeon was made aware of the problem by being confronted with his chart and was able to draw conclusions for future operations. The development was similar for surgeon G. After his 100th operation, a steep increase in complications and break of the upper boundary

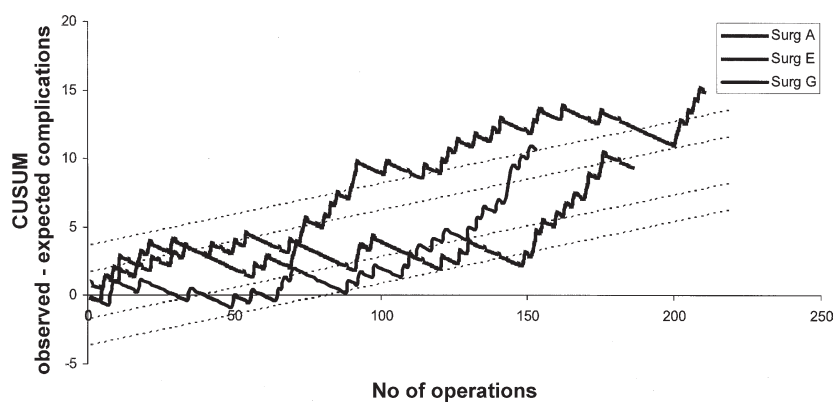

Figure 4. CUSUM charts of surgeons with intermediate experience (with $80 \%$ and $95 \%$ boundary lines). CUSUM, Cumulative sum. 


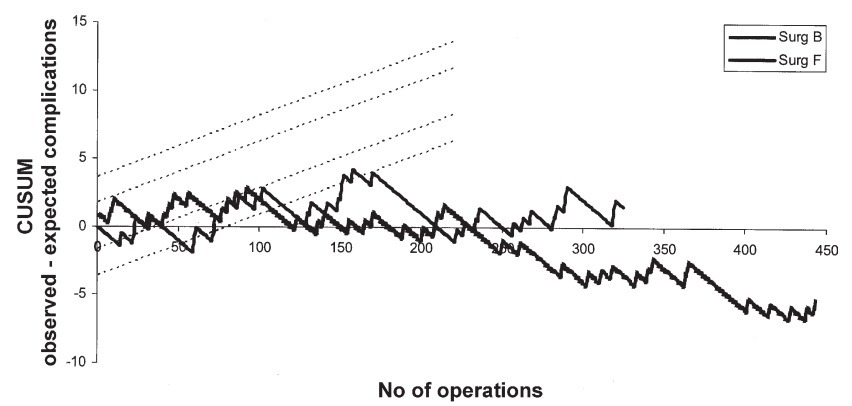

Figure 5. CUSUM charts of surgeons with large experience (with $80 \%$ and $95 \%$ boundary lines). CUSUM, Cumulative sum.

after 150 operations were observed. The main problem was a high number of necessary conversions to sternotomy, partly because of improper patient selection (Figure 4).

Surgeons with large experience. Approximately half of all MIDCAB operations at our institution were performed by surgeons B and F. They performed and still perform the operation on a regular basis, which results in an overall low complication rate and a stable performance over time (Figure 5).

Influence of the frequency of operations. Some experienced surgeons showed a marked increase in perioperative complications after having passed the initial learning phase. Subsequently, the influence of the frequency with which MIDCAB was performed was investigated. Examples are shown in Figure 6. The CUSUM failure value is plotted against the number of the operations. In addition, the average time between 2 operations in days (the reciprocal of the frequency of this operation) is shown by the solid line and the scale on the right. As can be seen by the density of the operations, surgeon $\mathrm{F}$ has regularly performed MIDCAB operations and thus stabilized his failure rate around the expected level of approximately $10 \%$. Surgeon A, initially performing MIDCAB operations regularly, also has an initial learning curve. After that, he has a stable failure rate from operation 25 to operation 150 . With decreasing frequency the failure rate increases again (Figure 6).

These figures underline the importance of regular specialized surgical practice and training.

\section{Discussion}

The importance of quality control in cardiac surgery is widely accepted. Yet it remains a sensitive subject, because it means dealing with failures and imperfections. On the other hand, the thorough analysis of failures can be a powerful means toward improvement of overall performance. Despite the potential for improving the quality of surgical performance, the evaluation of human factors and analysis of surgical errors have found little echo in the cardiac surgical literature. De Leval and colleagues ${ }^{1}$ pioneered the monitoring of surgical performance in a comprehensive multicenter study in pediatric cardiac surgery. Carthey and colleagues ${ }^{2}$ published a research review on the same topic. Novick and colleagues ${ }^{4,5,9}$ recently used the CUSUM method for describing the performance of single surgeons in off-pump coronary artery bypass grafting. The

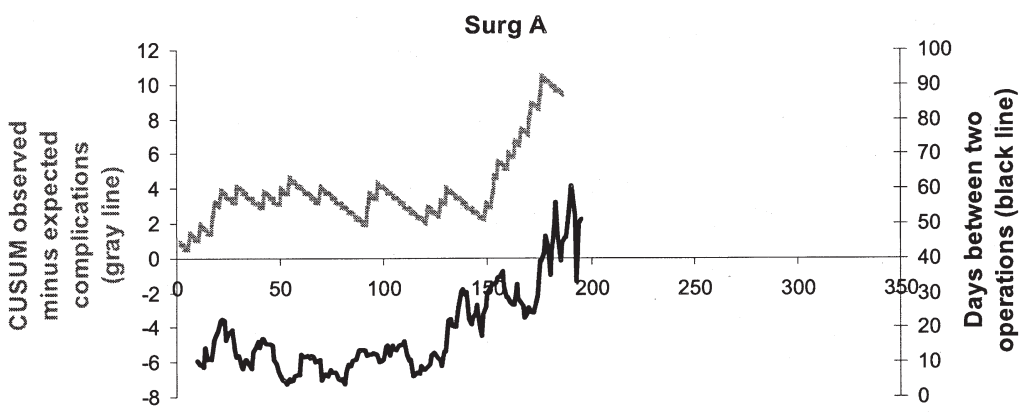

No of Operations

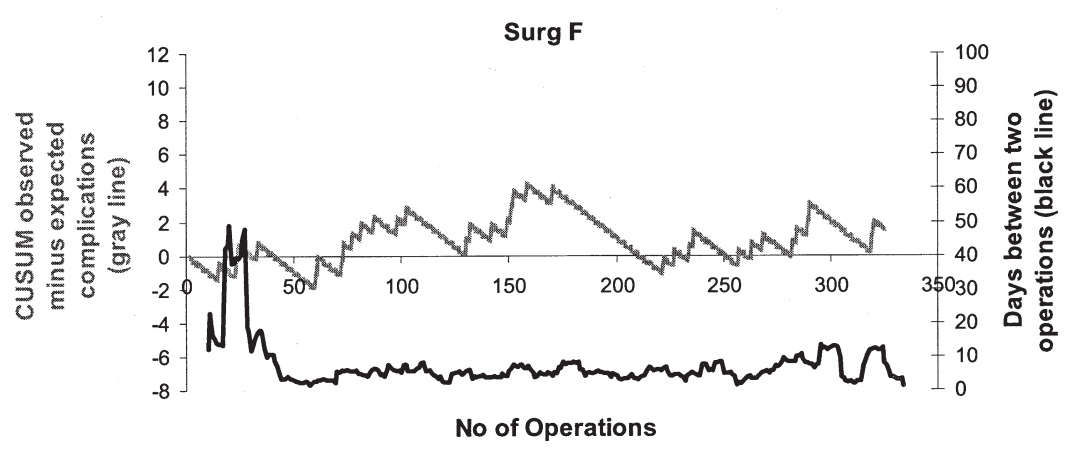

Figure 6. Influence of the frequency of operations. The same CUSUM curves as in Figures 4 and 5 are plotted against the average time in days (right $y$-axis) between 2 MIDCAB operations. Although this is not a statistically proven method, the influence of longer time intervals became obvious during the data analysis. $C U$ SUM, Cumulative sum. 
utility of the CUSUM method has also been shown for comparing results in transplant surgery by Rogers and colleagues ${ }^{10}$ and Axelrod and colleagues. ${ }^{11}$

The correlation between surgical volume and quality has been investigated, particularly concerning postoperative mortality. Although some groups report data that strongly support the concentration of certain surgical procedures to high-volume centers and surgeons, ${ }^{12-14}$ others question this evidence because of their own experience. ${ }^{15-18}$ In this study not only the surgical caseload and the influence on mortality but also the effect of changing frequency of performing MIDCABs was evaluated.

The traditional way of surgical audits with retrospective analysis of outcome data and statistical testing is an appropriate method of confirming outlying performance when the difference has reached a magnitude of statistic significance. ${ }^{19}$ In contrast, with CUSUM failure analysis, sudden changes in postoperative patient outcome can be detected quickly, and surgeons can be made aware of a deterioration in their performance. CUSUM charts are easily calculated, and their interpretation allows for an "online" monitoring of surgical performance.

Limitations of this study include its retrospective nature in the beginning. From 2005 onward, data were entered prospectively. No risk adjustment was applied. The theoretic and practical advantages of using risk-adjusted curves have been well described. ${ }^{3,20}$ They are particularly useful whenever an appropriate risk model is available (eg, EuroSCORE for predicted perioperative mortality). In a recent publication, Novick and colleagues ${ }^{20}$ applied an institutional logistic regression model for adverse outcome to calculate risk-adjusted CUSUM curves. They found an advantage over the non-risk-adjusted curves, particularly in avoiding inappropriate alarm signals, although the clinical significance was only moderate. However, a risk-adjusted analysis can only be as good as the underlying risk prediction model. For retrospective data such as in the current study, we were reluctant to apply a similar risk prediction model because not all possible influencing factors were recorded.

The 3 major conclusions of this study are as follows: (1) Even for experienced surgeons, there is a learning curve for the MIDCAB procedure that levels after approximately 100 operations. (2) Thereafter, performance depends not only on the absolute number of the performed operations ("high volume history") but also on the frequency; that is, the level of skill will not automatically be maintained. (3) Technically demanding operations such as the MIDCAB procedure might not be opportune for every surgeon. These conclusions seem logical and self-evident; however, CUSUM analysis comparing the results of different surgeons provides scientific and statistic evidence for these widely acknowledged presumptions.

\section{Conclusions}

MIDCAB has proven to be an excellent method for singlevessel coronary artery disease with a low overall complication rate, a high patency rate, and an excellent long-term survival. ${ }^{21}$ Still, there is room for improvement. Data are now being updated on a monthly basis and presented to the involved surgeons. Future analyses will show the value of this practice.

\section{References}

1. De Leval MR, Carthey J, Wright DJ, Farewell VT, Reason JT. Human factors and cardiac surgery: a multicenter study. J Thorac Cardiovasc Surg. 2000;119:661-72.

2. Carthey J, de Leval MR, Reason JT. The human factor in cardiac surgery: errors and near misses in a high technology medical domain. Ann Thorac Surg. 2001;72:300-5.

3. Rogers CA, Reeves BC, Caputo M, Ganesh JS, Bonser RS, Angelini GD. Control chart methods for monitoring cardiac surgical performance and their interpretation. J Thorac Cardiovasc Surg. 2004;128: 811-9.

4. Novick RJ, Fox SA, Stitt LW, Kiaii BB, Swinamer SA, Rayman R, et al. Assessing the learning curve in off-pump coronary artery surgery via CUSUM failure analysis. Ann Thorac Surg. 2002;73:358-62.

5. Novick RJ, Stitt LW. The learning curve of an academic cardiac surgeon: use of the CUSUM method. J Card Surg. 1999;14:312-20.

6. Novick RJ, Fox SA, Stitt LW, Swinamer SA, Lehnhardt KR, Rayman $\mathrm{R}$, et al. Cumulative sum failure analysis of a policy change from on-pump to off-pump coronary artery bypass grafting. Ann Thorac Surg. 2001;72:1016-21.

7. Blackstone EH. Monitoring surgical performance. J Thorac Cardiovasc Surg. 2004;128:807-10.

8. Diegeler A, Spyrantis N, Matin M, Falk V, Hambrecht R, Autschbach $\mathrm{R}$, et al. The revival of surgical treatment for isolated proximal high grade LAD lesions by minimally invasive coronary artery bypass grafting. Eur J Cardiothorac Surg. 2000;17:501-4.

9. Novick RJ, Fox SA, Kiaii BB, Stitt LW, Rayman R, Kodera K, et al. Analysis of the learning curve in telerobotic, beating heart coronary artery bypass grafting: a 90 patient experience. Ann Thorac Surg. 2003;76:749

10. Rogers CA, Ganesh JS, Banner NR, Bonser RS. Cumulative risk adjusted monitoring of 30-day mortality after cardiothoracic transplantation: UK experience. Eur J Cardiothorac Surg. 2005;27:1022-9.

11. Axelrod DA, Guidinger MK, Metzger RA, Wiesner RH, Webb RL, Merion RM. Transplant center quality assessment using a continuously updatable, risk-adjusted technique (CUSUM). Am J Transplant. 2006; 6:313-23.

12. Dibra A, Kastrati A, Schuhlen H, Schomig A. The relationship between hospital or operator volume and outcomes of coronary patients undergoing percutaneous coronary interventions. Z Kardiol. 2005;94 231-8.

13. Hannan EL, Wu C, Ryan TJ, Bennett E, Culliford AT, Gold JP, et al. Do hospitals and surgeons with higher coronary artery bypass graft surgery volumes still have lower risk-adjusted mortality rates? Circulation. 2003;19;108:795-801.

14. Shahian DM, Normand SL. The volume-outcome relationship: from Luft to Leapfrog. Ann Thorac Surg. 2003;75:1048-58.

15. Welke KF, Barnett MJ, Sarrazin MS, Rosenthal GE. Limitations of hospital volume as a measure of quality of care for coronary artery bypass graft surgery. Ann Thorac Surg. 2005;80:2114-9.

16. Zacharias A, Schwann TA, Riordan CJ, Durham SJ, Shah A, Papadimos TJ, et al. Is hospital procedure volume a reliable marker of quality for coronary artery bypass surgery? A comparison of risk and propensity adjusted operative and midterm outcomes. Ann Thorac Surg 2005;79:1961-9.

17. Rathore SS, Epstein AJ, Volpp KG, Krumholz HM. Hospital coronary artery bypass graft surgery volume and patient mortality, 1998-2000. Ann Surg. 2004;239:110-7. 
18. Papadimos TJ, Habib RH, Zacharias A, Schwann TA, Riordan CJ, Durham SJ, et al. Early efficacy of CABG care delivery in a low procedure-volume community hospital: operative and midterm results. BMC Surg. 2005;5:10.

19. Kang N, Tsang VT, Gallivan S, Sherlaw-Johnson C, Cole TJ, Elliott MJ, et al. Quality assurance in congenital heart surgery. Eur J Cardiothorac Surg. 2006;29:693-7.

20. Novick RJ, Fox S, Stitt LW, Forbes TL, Steiner S. Direct comparison of risk-adjusted and non-risk-adjusted CUSUM analyses of coronary artery bypass surgery outcomes. J Thorac Cardiovasc Surg. 2006;132: 386-91.

21. Holzhey DM, Jacobs S, Mochalski M, Walther T, Thiele H, Mohr FW, et al. Seven year follow-up after minimally invasive direct coronary artery bypass experience with more than 1300 patients. Ann Thorac Surg. 2007:83:108-14.

\section{Appendix}

Adapted from Rogers and colleagues. ${ }^{3}$ CUSUM charts and boundary lines were constructed using 4 parameters:

$\mathrm{p}_{0}$ the acceptable complication rate (in this article $\mathrm{p}_{0}=0.1$ )

$\mathrm{p}_{1}$ the unacceptable complication rate (in this article $\mathrm{p}_{1}=0.2$ )

$\alpha$ probability of false alarm, ie, error of assuming that the complication rate has increased to $\mathrm{p}_{1}$ when, in fact, it has not (in this article $\alpha=0.05$ and $\alpha=0.2$ for upper boundaries)

$\beta$ probability of false reassurance, ie, error of assuming that the complication rate has not increased when, in fact, it has (in this article $\beta=0.05$ and $\beta=0.2$ for lower boundaries)
If $\mathrm{X}_{\mathrm{i}}$ indicates the outcome of the operation $\mathrm{I}$, with $\mathrm{X}_{\mathrm{i}}=1$ if a serious adverse event occurred and $X_{i}=0$ if it did not, the CUSUM of adverse events was defined as

(1) $\mathrm{S}_{\mathrm{n}}=\sum_{i=1}^{n}\left(\mathrm{X}_{\mathrm{i}}-p_{0}\right)$

The upper boundary $l_{1}$ (to detect an increase from $\mathrm{p}_{0}$ to $\mathrm{p}_{1}$ ) and the lower boundary $1_{0}$ (to assume a failure rate equal or less than $\mathrm{p}_{0}$ ) with an odds ratio corresponding to an increase in event rate from $\mathrm{p}_{0}$ to $\mathrm{p}_{1}$ were calculated as

(2) $\mathrm{l}_{1}=\mathrm{ix}\left(\mathrm{s}-\mathrm{p}_{\mathrm{o}}\right)+\mathrm{h}_{1}$ and

(3) $1_{0}=\mathrm{ix}\left(\mathrm{s}-\mathrm{p}_{\mathrm{o}}\right)-\mathrm{h}_{\mathrm{O}}$

with

(4) $s=\frac{\ln \left(\frac{1-p_{0}}{1-p_{1}}\right)}{\ln (O R)}$

(5) $\ln (O R)=\ln \frac{p_{1}\left(1-p_{0}\right)}{p_{0}\left(1-p_{1}\right)}$

(6) $h_{0}=\frac{\ln \left(\frac{1-\alpha}{\beta}\right)}{\ln (O R)}$

(7) $h_{1}=\frac{\ln \left(\frac{1-\beta}{\alpha}\right)}{\ln (O R)}$ 


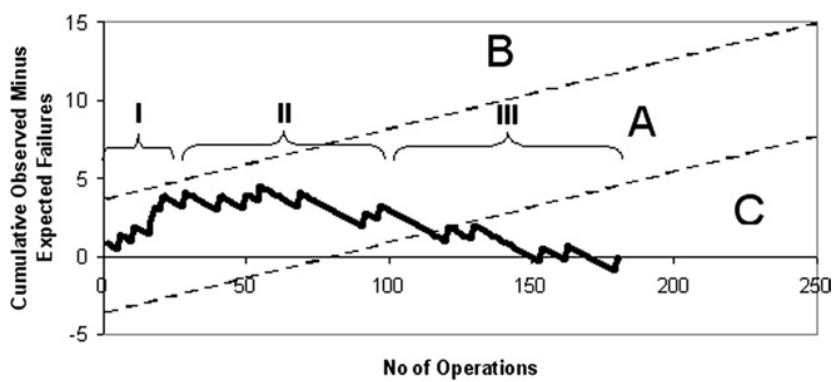

Figure E1. CUSUM failure chart of a typical learning curve. The curve was constructed as cumulative observed minus expected failure graph using an acceptable failure rate of $10 \%\left(p_{0}=0.1\right)$. The unacceptable failure rate was set to $20 \%\left(p_{1}=0.2\right)$ for the boundary lines, the probability $\alpha$ of concluding that the failure rate has increased when it has not (false-positive) was set to $5 \%(\alpha=0.05)$, and the probability $\beta$ of concluding that the failure rate has not increased when it has (false-negative) was set to $5 \%(\beta=0.05)$. The typical learning curve of a surgeon consists of an incline (I) indicating a failure rate higher than $p_{0}$, a horizontal run (II) with a failure rate around $p_{0}$, and, with growing experience, a typical decline (III) for a failure rate less than $p_{0}$. As long as the curve stays in between the boundary lines (area $A$ ) the process is statistically inconclusive. If it crosses the upper boundary (toward area B), the conclusion that the failure rate has increased to an unacceptably high level $p_{1}$ can be made (with the uncertainty $\alpha$ ). On the other hand, if the curve enters area $\mathrm{C}$ it is statistically significant that the failure rate is $p_{0}$ or less (with the uncertainty $\beta$ ).

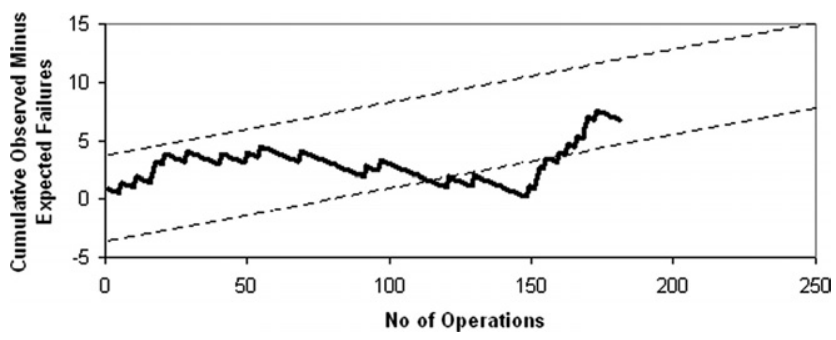

Figure E2. After the typical learning process and the lower boundary was crossed, the process seems to be completely in control. After approximately operation 150, an obvious accumulation of failures occurs. The surgeon has built up a credit; thus, the CUSUM curve only enters the inconclusive zone.

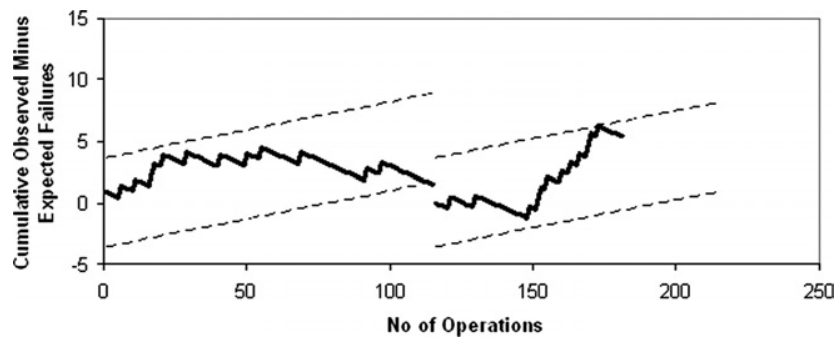

Figure E3. Several authors ${ }^{3}$ recommend resetting the zero line and the boundaries once the lower boundary is crossed. This way, the visually obvious increase in the failure rate becomes statistically evident. 